\title{
BMJ Open Development and testing of the shared decision-making attitudes scale among nurses in Taiwan: a cross-sectional scale development study
}

\author{
Hsiu-Chin Hsu, ${ }^{1,2}$ Shu-Chuan Lin, ${ }^{3}$ Yu-Hsia Lee, ${ }^{3}$ Hon-Yen Wu (D) ,4,5,6,7 \\ Pao-Yu Wang, ${ }^{8}$ Jiun-Yi Li, ${ }^{3}$ Mei-Hsiang Lin (iD ${ }^{9}$
}

To cite: Hsu H-C, Lin S-C, Lee Y-H, et al. Development and testing of the shared decision-making attitudes scale among nurses in Taiwan: a cross-sectional scale development study. BMJ Open 2021;11:e044733. doi:10.1136/ bmjopen-2020-044733

- Prepublication history and additional supplemental material for this paper are available online. To view these files, please visit the journal online (http://dx.doi.org/10.1136/ bmjopen-2020-044733).

Received 13 September 2020 Accepted 26 August 2021

Check for updates

(C) Author(s) (or their employer(s)) 2021. Re-use permitted under CC BY-NC. No commercial re-use. See rights and permissions. Published by BMJ.

For numbered affiliations see end of article.

Correspondence to

Dr Mei-Hsiang Lin;

mhlin5452@gmail.com

\section{ABSTRACT}

Objective Shared decision-making (SDM) enhances medical care, but an appropriate tool for evaluating nursing staff's attitudes towards SDM in clinical practice is lacking. The objective of this study is to develop the Nursing Shared Decision-Making Attitude (NSDMA) scale and verify its psychometric properties.

Design Instrument design study.

Participants A sample of 451 nursing staff. Intervention This study comprised two phases. In phase 1, qualitative research and expert content validity were adopted to develop the first draft of the scale. In phase 2, Taiwanese nursing staff were recruited through convenience sampling, and the sample was divided into a calibration sample and a validation sample. An objective structured clinical examination of SDM attitudes was administered to 100 nursing staff to determine the scale's cut-off score.

Main outcome measurements Exploratory factor analysis and confirmatory factor analysis were used to obtain the underlying factors of the NSDMA scale; McDonald's omega value was used to determine the reliability; known-group validity was used to test the construct validity; and the receiver operating characteristic curve was adopted to determine the scale's cut-off score.

Results In total, two factors were identified from the instrument results, which were termed 'empathic communication' and 'mastery learning'. The McDonald's omega value of the overall scale was 0.92 . Knowngroup validity testing was performed based on the staff's participation in SDM courses and experience of SDM, and the results exhibited significant differences $(t=5.49, p<0.001 ; t=2.43, p<0.05)$. Based on the receiver operating characteristic curve, the optimal cut-off for SDM attitudes was determined as 48.5 points.

Conclusions The NSDMA scale enables the evaluation of SDM attitudes among clinical nursing staff and nursing managers; the results may serve as a reference for incorporation of SDM into nursing policy formulation.

\section{BACKGROUND}

Shared decision-making (SDM) is a mechanism through which health professionals and patients cooperate in the decisionmaking process during the administration of
Strengths and limitations of this study

- This is the first publication of a new research instrument to measure the shared decision-making attitude among nurses in clinical practice.

- The principles and processes used to develop the Nursing Shared Decision-Making Attitude scale included indepth interviews and verification of its psychometric properties.

- The participants in this study were recruited from a medical centre in one country.

medical care. ${ }^{1}$ This approach can positively affect patients' future medical care; it yields favourable health outcomes for patients and encourages rational use of medical resources. ${ }^{2}$ Nursing staff comprise a large portion of medical care professionals and are key members of their medical teams. Nursing staff are critical to SDM and formulate the basic concepts and principles related to the decision-making process. ${ }^{34}$ In clinical circumstances, nursing staff must apply SDM to address clinical care issues, such as in relation to diseases, disease coexistence and palliative care. ${ }^{56}$ The application of SDM for setting individual goals can help patients with diabetes and multiple comorbidities prioritise their treatment plans. ${ }^{57}$ Tariman et al discussed the role of the nursing staff in the SDM process for cancer care and discovered that the nursing staff assume different roles at different times and in different environments. Their results indicated that providing patient health education and side-effect treatment was the most critical role that nursing staff played, especially oncology nurses who attached considerable importance to participating in SDM. Tariman et al also reported that nursing staff may serve as health educators, advocators, information or data collectors, and psychological supporters, as well as 
treating symptoms and side effects and sharing information during the SDM process for cancer care. ${ }^{89}$ Moreover, several studies have revealed that a nursing staff possessing knowledge regarding skills and a positive attitude towards SDM can facilitate the SDM process. ${ }^{10}$ Forcino $e a^{11}$ investigated SDM knowledge and attitudes among physician assistants, nurse practitioners as well as physicians and discovered that despite limited knowledge, positive attitudes as an important constituent warrant SDM training across occupations and specialties. Along this line, healthcare providers' attitude towards SDM is an essential component to consider in patient-centred care; however, professionals rarely pay attention to patientcentred attitudes during the SDM processes. ${ }^{11} 12$

Therefore, it is crucial for educators to identify the degree of nurses' SDM attitudes and improve their attitudes through the implementation of educational programmes. Some literature has reported that there are no suitable measurements for evaluating SDM attitudes in current clinical nursing settings. ${ }^{13}$ Most of the tools were developed within a specific context, such as in a physician's practice. ${ }^{614-16}$ Hence, proper evaluation tools should be developed for SDM attitude among nursing staff. $^{8}$

The objective structured clinical examination (OSCE), which is being increasingly applied worldwide in various medical specialties, is a teaching method and an evaluation tool. ${ }^{17}$ Its content includes medical knowledge, skills and attitudes covering human achievement, performance in an OSCE taken early in the clinical course, and strongly predicts later clinical performance. ${ }^{18-20}$ The study also revealed that poor performance in the OSCE was strongly associated with poor performance later in other clinical examinations. ${ }^{18}$ Another study by Tucker Edmonds $e t a l^{20}$ used an OSCE to evaluate whether learners were able to use SDM in the trial of labour after caesarean counselling. They discovered that using OSCE testing constituted a useful strategy to evaluate and train residents in both basic and advanced communication skills to support the provision of patient-centred care. Importantly, the OSCE form of summative assessment, which was used at the end of any form of structured instruction, has been proven to be valid, comprehensive and reliable in evaluating the learner's ability to apply the body of knowledge or clinical skills encountered. ${ }^{21}$ Based on the above statements, the OSCE form of a summative assessment was used in this study to assess nurses' SDM attitude.

A patient's cultural background should be considered when conducting SDM. ${ }^{21-23}$ This holds particularly true when patients are strongly influenced by their local culture. When their patients include a diversity of ethnic and cultural backgrounds, nursing staff involved in SDM cannot design plans according to a single criterion. In addition, the criteria applied in Western countries may not be suitable in Taiwan, which has its own irreplaceable local experience. Notwithstanding, many current studies have developed SDM assessment tools, ${ }^{6}{ }^{14-16}$ but most SDM scales have focused on the doctor and the patient only. There were few studies that discussed the SDM attitudes of front-line nursing staff. Therefore, the present study aimed to construct a new tool to measure nurses' SDM attitudes. The resulting scale can serve as a reference for planning of inservice education to enhance clinical nurses' SDM-related abilities.

\section{METHODS}

\section{Design and participants}

This study comprised two phases. Initially, purposive sampling was used to recruit participants from a medical centre in northern Taiwan, which owns 2089 beds. Nursing staff who met the following inclusion criteria were recruited: (1) completed formal nursing education and obtained a practice licence and (2) at least 1 year of work experience at the current medical institution. Nursing staff with a confirmed diagnosis of cancer or depression were excluded. According to Letvak et al, ${ }^{24}$ nurses with depression or malignant disease are likely to be negatively affected by the illness themselves, and their illness may also affect their coworkers and potentially the quality of the care they provide. ${ }^{25}$ For this reason, these nurses were excluded from this study. As a result, 430 eligible nurses were invited to participate in this study.

Phase 1 involved qualitative interviews with 21 nursing staff who met the inclusion criteria, followed by an analysis of interview results and the development of the first draft of the scale based on expert content validity. In phase 2, a descriptive cross-sectional research design was adopted to test the scale's reliability and validity. The sample size for validating the scale was based on a subject to item ratio between 5:1 and 10:1. ${ }^{26} 27$

A total of 430 participants were divided into two subsamples using this two-stage process. Participants in the first stage, the calibration sample (150 individuals), was used to validate and modify the factor structure constructed in the previous study. ${ }^{28}$ The validation sample (280 individuals) was used to verify the adequacy and stability of the factor structures that were developed from the calibration sample. ${ }^{29}$ The study developed the OSCE based on relevant literature. ${ }^{30}$ Teaching plans and scripts were designed and compiled with a focus on actual case examples with clinical teaching significance. This study finalised SDM attitude checklist for examiner assessment. The examiner assigned the score based on the interaction between the participant and the standard patient (SP). The higher the score nurses gained, the better the nurse's possessed overall attitude towards SDM. Additionally, the cut-off score of the Nursing Shared Decision-Making Attitude (NSDMA) scale was used to determine the OSCE pass or fail in the present study.

\section{Procedures}

Scale development (phase 1)

In phase 1, semistructured interview guidelines were used as the basis for drafting the NSDMA scale. The interview guidelines comprised the following questions: (1) What 
is your understanding of the concept of SDM? (2) Who do you think should make medical treatment decisions? (3) What is the role of SDM in clinical care plans for individual patients? (4) How do you apply SDM in the daily care of each patient? (5) What roles do the nursing staff play in the SDM process?

The interviews were audio-recorded and then transcribed. Interview data were transformed into texts through content analysis, which were then classified according to their narrative content. The original statements and languages of the interviewees were retained as much as possible, and qualitative research experts were hired to discuss the classification, thereby ensuring the appropriateness and accuracy of the content classification. Twenty-one nurses participated in the qualitative study. The findings yielded the following three themes, covering seven categories: (1) knowledge regarding SDM (gaining relevant professional knowledge, reading and integrating evidence, and editing media related to $\mathrm{SDM})$; (2) trigger discussion and coordination (forming a cooperative SDM team as well as trigger and coordination regarding SDM); and (3) respect of sociocultural factors (patients' values with respect to their cultural background, and the cultural differences of patients and families). The results from the qualitative study were used to construct a pool of items for the NSDMA scale.

On the basis of the qualitative content analysis results and relevant literature, we proposed 19 questionnaire items for the first draft of the NSDMA scale. Five experts, two nursing professors who specialised in scale construction and three nurses with more than 10 years of clinical care and SDM experience, were invited to assess the content validity of the draft scale based on the relevance, accuracy and wording of the 19 items. The item-level content validity index (I-CVI) of the scale was 0.95 and the scale-level content validity index (S-CVI) was 0.90. Experts also suggested wording amendments. For example, 'Nursing staff must have communication skills' (question 1) was changed to 'Ability to communicate with the medical team'. In phase 1 , we revised the text, but we did not change the total number of questionnaire items. A 5-point Likert scale, ranging from 1 (strongly disagree) to 5 (strongly agree), was employed as the evaluation method. The higher the score for each item, the more inclined the respondents were towards the SDM attitude represented by the item.

\section{Validation and receiver operating characteristic curve analysis of} the NSDMA scale (phase 2)

In phase 2, we tested the scale's reliability and validity and determined a cut-off. The reliability of the scale was measured using internal consistency (Cronbach's $\alpha$ ). For validity, exploratory factor analysis (EFA) of the calibration sample (150 valid questionnaires) and confirmatory factor analysis (CFA) of the validation sample (280 valid questionnaires) were performed to determine the conformity of the scale's factor structure with the theoretical model. Subsequently, a known-group validity test was conducted to assess the construct validity. Finally, the receiver operating characteristic (ROC) curve was used to determine the scale's cut-off score.

\section{Statistical analysis}

Data were analysed using SPSS V.20.0 and AMOS V.22.0 for Windows (IBM, Armonk, New York, USA). McDonald's omega value was used to determine the internal consistency of the NSDMA scale. To assess the scale's reliability and validity, we first conducted EFA of the calibration sample, in which the principal component was used for factor extraction. The number of factors was determined based on the number of eigenvalues greater than 1 . The varimax oblique rotation method was applied to extract the factor loadings, of which the standard questionnaire item selection was set to $>0.50$, based on the practical significance. ${ }^{29} 31$ After scale analysis, cross-loading between questionnaire items and the factors required expert discussion to determine whether the item should be removed and a reanalysis of the goodness of fit of the factors was performed ${ }^{29}$ Subsequently, AMOS V.22.0 was used to perform CFA of the validation sample; the convergent validity and reliability were verified to ensure the internal quality of the scale.

Nowadays, the SDM courses of training that nurses received comprised three units: the core concepts of SDM, an introduction to patient decision aids, as well as application and implementation of SDM. ${ }^{32}$ The SDM attitude score obtained by the participants undergoing SDM courses would be higher than that of the participants who did not receive SDM courses. ${ }^{33}$ Therefore, known-group validity was examined using independent samples t-test to determine the differences between the total NSDMA scores for the two groups (undergoing SDM courses and not receiving SDM courses). Finally, to determine the scale's cut-off score, an OSCE for SDM attitudes was administered to 100 nursing staff who met the inclusion criteria. According to the Angoff method, the total score of the OSCE is 24 points in the present study and the passing standard is 16 points. ${ }^{17}$ The ROC curve was employed to determine the cut-off and to provide a reference for possible scores. The ROC analysis model fit was evaluated using Nagelkerke's $R^{2}{ }^{34}$

\section{Patient and public involvement}

No patients were involved.

\section{Ethical considerations}

After obtaining approval from the institutional review board, we contacted the administration office to request permission to explain our research objective and participant rights to the nursing staff during the shift handover of each department. Nursing staff who met the inclusion criteria either scheduled an interview time with the researcher or completed the self-administered questionnaire anonymously. Completed questionnaires were placed into a questionnaire return box at each department to be retrieved by the research assistant. The study was conducted after obtaining signed informed consent from each participant. 


\section{RESULTS}

\section{Demographics of study participants}

A total 430 nursing staff participated in the quantitative study, who had a mean age of 42.01 years $(\mathrm{SD}=10.38$ years $)$ and a mean nursing experience of 20.34 years $(\mathrm{SD}=10.87$ years). Majority of the participants had college education $(\mathrm{n}=255,59.3 \%)$, were married $(\mathrm{n}=252,58.6 \%)$ and were ranked N3 ( $\mathrm{n}=176,40.9 \%)$. Finally, 48.1\% $(\mathrm{n}=207)$ and $54.4 \%(\mathrm{n}=234)$ of the nursing staff had participated in SDM courses and had had SDM experience, respectively.

\section{Psychometric properties of the NSDMA scale \\ EFA results for the calibration sample}

The Kaiser-Meyer-Olkin (KMO) measure of sampling adequacy for the scale was 0.94 and Bartlett's test of sphericity yielded a significant result $(\mathrm{p}<0.001)$, indicating that factor analysis was applicable to the scale sample. In the preliminary results, three factors were extracted and explained $70.79 \%$ of the variance. However, factor 3 comprised only item 8 , 'unwillingness to intervene in medical treatment-oriented issues', and thus failed to exhibit the characteristics of the dimension it represented. Therefore, we deleted item 8 and reanalysed the sample. EFA resulted in two factors with a total of 18 items. The eigenvalue of factor 1, which explained $57.00 \%$ of the variance, was 9.25. Based on the questionnaire item content, factor 1 was named 'empathic communication' and comprised eight items. The eigenvalue of factor 2, which explained $8.04 \%$ of the variance, was 8.87 . Based on the questionnaire item content, factor 2 was named 'mastery learning' and comprised 10 items (table 1).

\section{CFA for the validation sample}

The goodness of fit of the two-factor model developed in phase 1 was assessed. CFA of the 18-item NSDMA scale revealed that the model's goodness of fit failed to meet the required standard. Therefore, the modification index (MI) provided by AMOS V.22.0 was used for the model modification test. Items with a factor loading of $<0.50$ were deleted. Items with higher MI values were also deleted. In a chronological order, items $16,1,6,14,17,18$ and 12 were removed. Because the $\chi^{2}$ value decreased by 630.103 from $771.300(\mathrm{df}=134)$ to $141.197(\mathrm{df}=43)$ and because various goodness-of-fit indices improved, this model was selected as the final model. Table 2 shows the convergent validity of the scale. The standardised factor loadings $(\lambda)$ of all the observed variables and the corresponding latent variables ranged from 0.60 to 0.80 . Although the $\lambda$ values of items 5, 7, 15 and 19 were less than the standard, they still yielded a practical significance of 0.50 . The reliability values of the individual observed variables $\left(R^{2}\right)$ ranged from 0.36 to 0.97 . The composite reliability (sometimes called construct reliability; CR) is a measure of internal consistency in scale items, much like Cronbach's $\alpha$ (Netemeyer et al, 2003). ${ }^{35}$ The CR of the two latent variables was 0.84 and 0.87 , respectively, and the average variance extracted was 0.52 for both latent variables. Figure 1 presents the standardised estimates of CFA for validation
Table 1 Exploratory factor analysis for the calibration sample $(n=150)$

\begin{tabular}{|clcl|}
\hline Items & Factor $\mathbf{1}$ & Factor 2 \\
\hline 2 & $\begin{array}{l}\text { Eager to coordinate doctor-patient } \\
\text { and doctor-nurse communication. }\end{array}$ & 0.90 \\
\hline $1 \quad \begin{array}{l}\text { Eager to communicate with the } \\
\text { medical team. }\end{array}$ & 0.90 \\
\hline $4 \quad \begin{array}{l}\text { Eager to implement patient- } \\
\text { centred care. }\end{array}$ & 0.86 \\
\hline $3 \quad \begin{array}{l}\text { Eager to respect and empathise } \\
\text { with patients' preferences and } \\
\text { values. }\end{array}$ & 0.84 \\
\hline
\end{tabular}

$5 \quad$ Eager to remain calm when explaining the medical decisionmaking options and alternatives to patients and their families.

6 Eager to suggest the most 0.85 appropriate treatment for each patient.

\begin{tabular}{|c|c|c|c|}
\hline 17 & $\begin{array}{l}\text { Eager to cooperate with the } \\
\text { medical team to enhance patient } \\
\text { treatment. }\end{array}$ & 0.55 & \\
\hline 7 & $\begin{array}{l}\text { Eager to provide patients with } \\
\text { high-quality information on } \\
\text { different treatments (ie, empirical } \\
\text { data). }\end{array}$ & 0.55 & \\
\hline 13 & $\begin{array}{l}\text { Eager to control the progress of } \\
\text { decision-making. }\end{array}$ & & 0.88 \\
\hline 16 & $\begin{array}{l}\text { Eager to advocate for patients' } \\
\text { treatment decisions. }\end{array}$ & & 0.83 \\
\hline 10 & $\begin{array}{l}\text { Eager to consider the needs of } \\
\text { patients in addition to medical } \\
\text { care. }\end{array}$ & & 0.77 \\
\hline 14 & $\begin{array}{l}\text { Eager to assess and analyse the } \\
\text { needs and difficulties in patients' } \\
\text { decision-making process. }\end{array}$ & & 0.68 \\
\hline 18 & $\begin{array}{l}\text { Eager to confirm patients' clinical } \\
\text { decisions. }\end{array}$ & & 0.63 \\
\hline 15 & $\begin{array}{l}\text { Eager to use SDM tools to assist } \\
\text { patients in making informed } \\
\text { choices, including advantages and } \\
\text { disadvantages. }\end{array}$ & & 0.66 \\
\hline 12 & $\begin{array}{l}\text { Eager to participate in the medical } \\
\text { care process together with patients } \\
\text { and their families. }\end{array}$ & & 0.63 \\
\hline 9 & $\begin{array}{l}\text { Eager to assist and guide patients } \\
\text { in discussing their conditions and } \\
\text { making medical decisions step by } \\
\text { step. }\end{array}$ & & 0.65 \\
\hline 19 & $\begin{array}{l}\text { Eager to participate in SDM } \\
\text { training courses organised by } \\
\text { medical institutions. }\end{array}$ & & 0.56 \\
\hline \multirow[t]{4}{*}{11} & $\begin{array}{l}\text { Eager to guide patients step by } \\
\text { step to discuss their condition and } \\
\text { make medical decisions. }\end{array}$ & & 0.55 \\
\hline & Eigenvalues & 9.25 & 8.87 \\
\hline & Percentage of variance & 57.00 & 8.05 \\
\hline & $\begin{array}{l}\text { Cumulative of total variance } \\
\text { explained }(\%)\end{array}$ & 57.00 & 65.05 \\
\hline
\end{tabular}

SDM, shared decision-making. 
Table 2 Factor analysis for the validation sample $(n=280)$

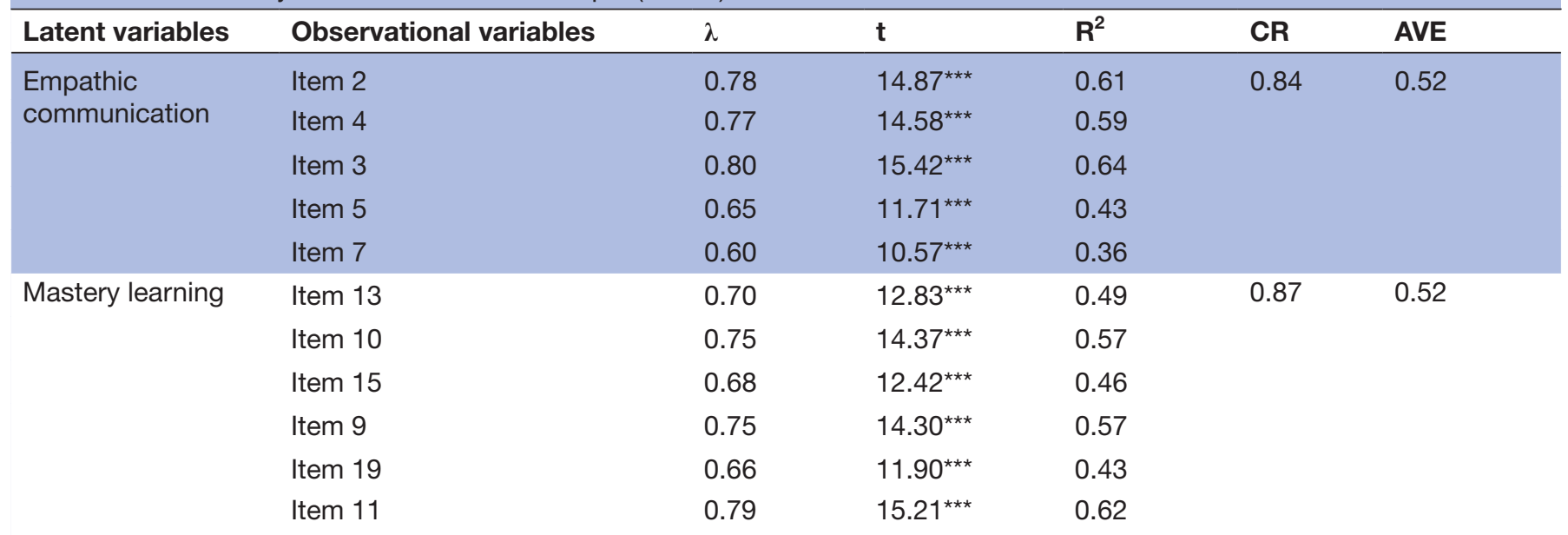

${ }^{* * *} \mathrm{P}<0.001$; all factor loadings were statistically significant at the $\mathrm{p}<0.001$ level.

$\lambda$, standardised factor loading; AVE, average variance extracted; CR, construct (component/composite) reliability; $\mathrm{R}^{2}$, reliability of item (also called square multiple correlation).

sample. The final version of the NSDMA scale is shown in online supplemental appendix A.

\section{Known-group validity}

The independent samples t-test results indicated that the total score of the NSDMA scale differed significantly between the groups who had and had not participated in SDM courses $(4.44 \pm 0.42$ and $4.20 \pm 0.48$, respectively; $\mathrm{t}=5.49, \mathrm{p}<0.001$ ) and between the groups with and without SDM experience (4.38 \pm 0.44 and $4.27 \pm 0.48$, respectively; $\mathrm{t}=2.43, \mathrm{p}<0.05)$. Accordingly, nursing staff who had

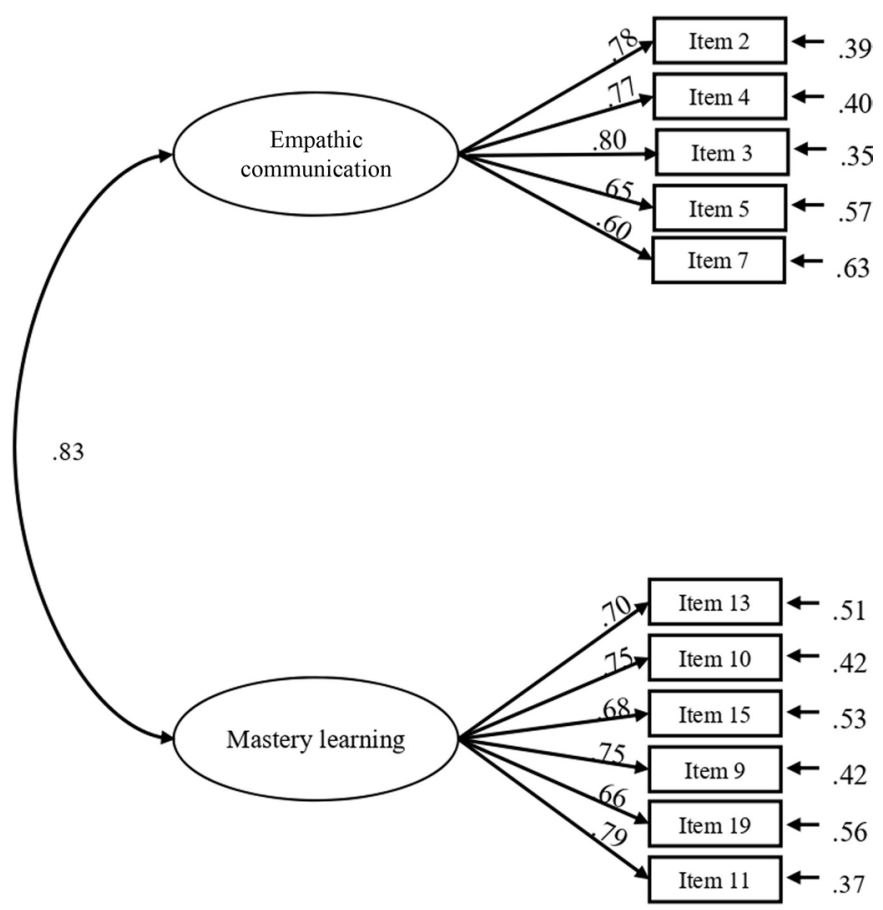

Figure 1 Standardised estimates of confirmatory factor analysis for the validation sample. Item number shown on the original item. participated in SDM courses and those with SDM experience received higher NSDMA scores.

\section{Reliability of the NSDMA scale}

The McDonald's omega values for the overall SDM attitude, empathetic communication as well as mastery learning were $0.92,0.87$ and 0.88 , respectively.

\section{ROC curve results}

The ROC curve was used to analyse the performance of the total NSDMA score in predicting the OSCE results and thus to determine the scale's cut-off score. Nagelkerke's $\mathrm{R}^{2}$ value was 0.79 , which indicated that the models were of acceptable explanatory value. The area under the ROC curve (AUC) was $61.6 \%$, with a CI of $49.4 \%$ to $73.7 \%$. The suggested cut-off scores for the NSDMA scale were proposed based on Youden's index (the optimal trade-off between sensitivity and specificity). ${ }^{36}$ The best

Table 3 Test accuracy index value of the NSDMA scale at different cut-off scores

\begin{tabular}{lll}
\hline Criterion & Sensitivity (\%) & Specificity (\%) \\
\hline 44.5 & 65.3 & 42.9 \\
\hline 45.5 & 62.5 & 53.6 \\
46.5 & 55.6 & 57.1 \\
47.5 & 52.8 & 64.3 \\
\hline $48.5^{\star}$ & 50.0 & 67.9 \\
\hline 49.5 & 44.4 & 71.4 \\
\hline 50.5 & 41.7 & 75.0 \\
\hline 51.5 & 37.5 & 78.6 \\
\hline 52.5 & 29.2 & 82.1 \\
\hline
\end{tabular}

*Indicates the optimal cut-off point for the scale.

NSDMA, Nursing Shared Decision-Making Attitude. 
cut-off for the NSDMA scale was 48.5 , with sensitivity of $50.0 \%$ and specificity of $67.9 \%$ (table 3 ).

\section{DISCUSSION}

SDM is becoming a nursing responsibility in clinical care, and caregivers' attitudes towards SDM affect their decisions about patient treatment. ${ }^{18} 37$ The aim of this study was to develop a local psychometric NSDMA scale to measure the SDM attitudes of Taiwanese clinical nursing staff. The first draft of the scale had an I-CVI of 0.95 and an S-CVI of 0.90, which met the requirements of Polit and Beck, ${ }^{38}$ stating that when the number of experts is more than five, the I-CVI value should be greater than 0.78 . Thus, the experts supported the correlations of most items with SDM attitudes. The scale initially had 19 questions, which were reduced to 11 in the final scale. This reduction was in agreement with DeVellis, ${ }^{39}$ who stated that, in the drafting stage, the total number of questionnaire items is usually approximately twice that of the items in the final scale. In addition, a cut-off for the NSDMA scale was determined to facilitate evaluation of the SDM attitudes of nursing staff and nursing managers and to serve as references for incorporation of SDM into nursing policy. The scale comprised two dimensions. The number of items in the first dimension was reduced from eight to five, and the dimension was named 'empathic communication' according to the items. This concurred with the findings of other studies that nursing staff should apply SDM with empathic communication when caring for patients with chronic diseases. Superior clinical communication skills constitute the basic skills required for establishing effective SDM (eg, establishing good rapport with patients, providing patient-oriented communication and risk communication, and being able to evaluate patients' values and preferences). ${ }^{4}$ The result identified important context that the promotion of SDM should be based on a good nurse-patient relationship. Particularly, in traditional Asian families, such as those in Taiwan, patients are more likely to play a silent role in the decision-making process because of traditional cultural pressure. ${ }^{40}$ Thus, nurses should be patient and listen to the expectations of patients during the SDM process.

The number of items in the second dimension was reduced from ten to six, and the dimension was named 'mastery learning' according to the items, which referred to nursing staff's use of research evidence, explanation of evidence and suggestions to meet the needs of patients in order to assist them with individual decision-making. This concurred with other studies indicating that the cultivation of SDM skills is a continuous, time-consuming process and that such skills yield continuous improvement. Therefore, SDM should be included as a lifelong learning course in medical care institutions. ${ }^{3} 4$ The premise of SDM is to provide evidence-related information to the patient and/or family members for subsequent communication and discussion. Therefore, the ability to search for and integrate empirical data is critical for the nursing staff in charge of SDM. Furthermore, auxiliary tools, including models and videos, are often needed to enhance the understanding of the patient and/or family members on the information given in the SDM process. The results confirm that the nursing staff are willing to adopt, search for and integrate empirical data, and that basic media editing abilities were critical issues for implementing SDM continuously.

The process of testing the scale's construct validity is detailed as follows. In the development of a new scale, data should be collected for EFA and CFA to ensure that measurement items are classified into their corresponding factors and to test the factor structure stability. ${ }^{25}$ Before performing factor analysis, the data should first be verified to ensure that they are suitable for factor analysis. We applied the KMO test to assess the net correlation coefficient between variables (a KMO value close to 1 indicates a low net correlation between the variables and indicates that factor analysis can be used for the extraction of common factors), and we employed Bartlett's test of sphericity to examine whether the correlation coefficients in the correlation matrix were significantly higher than $0 .{ }^{40}$ The KMO value of the scale was 0.94 , meeting the standard of $>0.90$ (signifying a marvellous result). The result of Bartlett's test of sphericity was significant $(p<0.001)$, indicating that the pretest data for this scale were suitable for factor analysis. ${ }^{41}$ Hair $e t a l^{29}$ reported that extracted factors are reliable when the factor loadings of all items are higher than 0.50 and the total variance explained is at least $64.75 \%$. The CFA of the original 18-item NSDMA scale revealed that the model's goodness of fit mostly failed to meet the required standards. Therefore, the MI provided by AMOS V.22.0 was used for the model modification test. Items with a factor loading of $<0.50$ were removed and items with higher MI values were also deleted. To avoid repeated concepts, items with a higher MI value were removed because this indicates a high degree of correlation with other items. ${ }^{42}$ Furthermore, convergent validity was determined based on the degree of correlation between variables within the same dimension, which is known as internal consistency validity. The evaluation criteria for the scale's convergent validity were as follows: (1) factor loading $\geq 0.7$; (2) square multiple correlation value $\geq 0.5$; (3) composite reliability $\geq 0.7$; and (4) average variance extracted $\geq 0.5$. ${ }^{17}$ The convergent validity test results for the NSDMA scale showed that the $\lambda$ values of all observed variables and the corresponding latent variables ranged from 0.60 to 0.80 . Although the $\lambda$ values of four items were less than the required standard, they still yielded a practical significance of $0.50 .{ }^{17}$ The reliability values of the individual observed variables $\left(\mathrm{R}^{2}\right)$ ranged from 0.36 to 0.97 , meeting the requirement that the latent variables of individual observed variables should be greater than $0.50 .^{29}{ }^{43}$ The construct validity values of the latent variables were 0.84 and 0.87 , respectively, both of which met the requirement of $\geq 0.70,{ }^{29}$ and the average variance extracted was 0.528 for the latent variables. For the majority of items, the average variance extracted 
met the $>0.50$ requirement for reliability. Therefore, the latent variables were more closely related to the observed variables than to errors. ${ }^{44}$ Based on these results, this scale has good convergent validity.

Known-group validity relates to a construct score that differs considerably within a known group. Therefore, two or multiple groups can be deliberately selected to compare the construct scores; a significant difference indirectly verifies the construct validity of the scale. ${ }^{45}$ In the present study, an independent samples t-test was conducted on a total of 430 participants, who were grouped based on their participation in SDM courses and their SDM experience. The results showed that those who had participated in SDM courses and those with SDM experience received higher total scores on the NSDMA scale. This verified the construct validity of the scale. Moreover, the coefficient omega estimates how reliably the total score for a test measures a single construct that is common to all items in the test, even if the test is multidimensional (eg, a test designed to produce a total score as well as subscale scores) ${ }^{46}$ According to Feißt et al, ${ }^{47}$ McDonald's omega values $>0.8$ can be interpreted as a good internal reliability. The McDonald's omega values of 'empathic communication' and 'mastery learning' were 0.87 and 0.88 , respectively, both of which indicated good reliability, and the McDonald's omega of the overall NSDMA scale was 0.92 , which indicated that the scale presented good reliability and good internal consistency. ${ }^{47}$

The AUC is a common method for evaluating the discriminative power of diagnostic tools. The AUC ranges from 0 to 1 , with higher values indicating greater discriminative power. ${ }^{48}$ In the present study, we generalised the NSDMA scale to the clinical practice of SDM by nursing staff. Research results indicated that the predictive power of the scale for passing the OSCE was close to the significance level $(p=0.074)$. The AUC was $61.6 \%$, with a CI of $49.4 \%$ to $73.7 \%$. Based on Youden's index (the maximum sensitivity and specificity), the optimal cut-off score for the NSDMA scale was determined as 48.5 , with sensitivity of $50.0 \%$ and specificity of $67.9 \%$; thus, the discriminatory performance for predicting OSCE results was average. ${ }^{34}$ Nagelkerke's $R^{2}$ value was 0.79 , indicating that the model has an acceptable explanatory value. ${ }^{36}$ The result enables nurses to self-report the appropriate attitudes in the SDM process because they are responsible for helping patients with medical decision-making. Nursing staff must reference research evidence, explain the evidence and make suggestions to meet the needs of patients during the decision-making process.

Although this study conducted rigorous reliability and validity testing, data were collected from a single medical institution. Future studies are suggested to expand data collection to obtain a larger sample and reduce the effects of confounding variables. Cross-validation validity should also be tested to verify the ideal inference validity. The ROC analysis method was applied in the present study to test the discriminative power of the scale; the results indicated that the discriminatory power of the NSDMA scale for predicting the OSCE results was average, based on Youden's index. The limited predictive ability of the multivariable models is also implied by the fairly low AUC. Despite this unsatisfactory finding, we viewed the sensitivity analyses as a relevant signal that should not be neglected. Accordingly, the applicability of the scale for evaluating SDM practice among clinical nursing staff should be considered with caution. Among the participating nursing staff, $51.9 \%$ had not participated in SDM courses and $54.4 \%$ had no SDM experience. To avoid the influence of different SDM experiences on the reliability and validity of the scale, future studies may consider recruiting only participants who have participated in SDM courses and those with actual clinical SDM experience to collect more representative samples. Assessing the stability of the analysis results would also facilitate the selection of a suitable cut-off score ${ }^{49}$ However, no local scale based on the SDM experiences of nursing staff was used to evaluate nursing staff's SDM attitude prior to this study. Therefore, currently the scale provides nurses with a localised tool for identifying whether suitability of NSDMA when evaluating meets the needs of patients during the decision-making process.

A number of issues have been raised through the results of this study which will be best explored in future research. First, since the convenience sampling was employed in this study, the finding of the geographical limitation of the sample restricts the extent of generalisation. A broader sample of nurses from varied medical institutions is recommended in a future study to test the applicability of the NSDMA scale. Furthermore, although the NSDMA scale and its subscales in this study exhibited acceptable reliability and validity scores, it is recommended to continue examining its reliability, using other alternative tests such as test-retest reliability. ${ }^{50}$

\section{CONCLUSION}

The process of scale development involved interviews and expert validity for developing the first draft and statistical analysis for measuring the reliability and validity of the scale. Finally, the NSDMA scale consisted of 2 subscales and a total of 11 questions about local nursing experiences. This scale, which revealed good reliability and validity, can be used to evaluate the SDM attitudes of clinical nursing staff and nursing managers, serve as a guide for incorporating SDM into nursing policy, and facilitate the design of inservice nursing education courses for SDM. It can serve as a useful evaluation to assess the SDM attitudes of nursing professionals and thereby provide an insight into patient care of nursing departments of hospitals in Taiwan.

\footnotetext{
Author affiliations

${ }^{1}$ Graduate Institute of Gerontology and Health Care Management, Chang Gung University of Science and Technology, Taoyuan, Taiwan, R.O.C

${ }^{2}$ Department of Internal Medicine, Chang Gung Memorial Hospital, Taoyuan, Taiwan, R.O.C

${ }^{3}$ Mackay Memorial Hospital, Taipei, Taiwan, R.O.C
} 
${ }^{4}$ Department of Internal Medicine, Far Eastern Memorial Hospital, New Taipei City, Taiwan, R.0.C

${ }^{5}$ School of Medicine, College of Medicine, National Yang Ming Chiao Tung University, Taipei, Taiwan, R.O.C

${ }^{6}$ Institute of Epidemiology and Preventive Medicine, College of Public Health, National Taiwan University, Taipei, Taiwan, R.0.C

${ }^{7}$ Department of Internal Medicine, National Taiwan University Hospital and College of Medicine, Taipei, Taiwan, R.0.C

${ }^{8}$ Department of Nursing, MacKay Junior College of Medicine Nursing and Management, Taipei, Taiwan, R.0.C

${ }^{9}$ School of Nursing, National Taipei University of Nursing and Health Sciences, Taipei, Taiwan, R.0.C

Contributors All authors named on this paper have contributed significantly and are in agreement with the content of this manuscript. H-CH, S-CL, Y-HL, H-YW, $\mathrm{P}-\mathrm{YW}, \mathrm{J}-\mathrm{YL}$ and $\mathrm{M}-\mathrm{HL}$ were involved in the conception of the work. S-CL, Y-HL, $\mathrm{P}-\mathrm{YW}$ and $\mathrm{J}-\mathrm{YL}$ were involved in data collection. $\mathrm{H}-\mathrm{CH}$ and $\mathrm{M}-\mathrm{HL}$ were involved in data analysis and interpretation. $\mathrm{H}-\mathrm{CH}, \mathrm{S}-\mathrm{CL}, \mathrm{Y}-\mathrm{HL}, \mathrm{P}-\mathrm{YW}$ and $\mathrm{M}-\mathrm{HL}$ were involved in drafting the article. $\mathrm{H}-\mathrm{CH}, \mathrm{S}-\mathrm{CL}, \mathrm{Y}-\mathrm{HL}, \mathrm{H}-\mathrm{YW}, \mathrm{P}-\mathrm{YW}, \mathrm{J}-\mathrm{YL}$ and $\mathrm{M}-\mathrm{HL}$ were involved in critical revision.

Funding The study received funding from the Ministry of Science and Technology of Taiwan (grant numbers: MOST 107-2511 H-227-003).

Disclaimer The funders had no role in study design, data collection and analysis, decision to publish, or preparation of the manuscript.

Competing interests None declared.

Patient consent for publication Not required.

Ethics approval Institutional review board approvals were obtained from MacKay Memorial Hospital (no. 18MMHIS123e).

Provenance and peer review Not commissioned; externally peer reviewed.

Data availability statement № data are available.

Supplemental material This content has been supplied by the author(s). It has not been vetted by BMJ Publishing Group Limited (BMJ) and may not have been peer-reviewed. Any opinions or recommendations discussed are solely those of the author(s) and are not endorsed by BMJ. BMJ disclaims all liability and responsibility arising from any reliance placed on the content. Where the content includes any translated material, BMJ does not warrant the accuracy and reliability of the translations (including but not limited to local regulations, clinical guidelines, terminology, drug names and drug dosages), and is not responsible for any error and/or omissions arising from translation and adaptation or otherwise.

Open access This is an open access article distributed in accordance with the Creative Commons Attribution Non Commercial (CC BY-NC 4.0) license, which permits others to distribute, remix, adapt, build upon this work non-commercially, and license their derivative works on different terms, provided the original work is properly cited, appropriate credit is given, any changes made indicated, and the use is non-commercial. See: http://creativecommons.org/licenses/by-nc/4.0/.

\section{ORCID iDs}

Hon-Yen Wu http://orcid.org/0000-0003-3121-3351

Mei-Hsiang Lin http://orcid.org/0000-0002-4188-6413

\section{REFERENCES}

1 Astbury R, Shepherd A, Cheyne H. Working in partnership: the application of shared decision-making to health visitor practice. $J$ Clin Nurs 2017;26:215-24.

2 Oshima Lee E, Emanuel EJ. Shared decision making to improve care and reduce costs. N Engl J Med 2013;368:6-8.

3 Ervin K, Blackberry I, Haines $\mathrm{H}$. Developing a taxonomy and mapping concepts of shared decision making to improve clinicians understanding. NCOAJ 2017;3:00063.

4 Friesen-Storms JHHM, Bours GJJW, van der Weijden T, et al. Shared decision making in chronic care in the context of evidence based practice in nursing. Int J Nurs Stud 2015;52:393-402.

$5 \mathrm{Yu} \mathrm{CH}$, Stacey D, Sale J, et al. Designing and evaluating an interprofessional shared decision-making and goal-setting decision aid for patients with diabetes in clinical care--systematic decision aid development and study protocol. Implement Sci 2014;9:16.

6 Zoffmann V, Harder I, Kirkevold M. A person-centered communication and reflection model: sharing decision-making in chronic care. Qual Health Res 2008;18:670-85.
7 Montori VM, Gafni A, Charles C. A shared treatment decisionmaking approach between patients with chronic conditions and their clinicians: the case of diabetes. Health Expect 2006;9:25-36.

8 Tariman JD, Katz P, Bishop-Royse J, et al. Role competency scale on shared decision-making nurses: development and psychometric properties. SAGE Open Med 2018;6:205031211880761.

9 Tariman JD, Mehmeti E, Spawn N, et al. Oncology nursing and shared decision making for cancer treatment. Clin $J$ Oncol Nurs 2016;20:560-3.

10 Mathijssen EGE, van den Bemt BJF, Wielsma S, et al. Exploring healthcare professionals' knowledge, attitudes and experiences of shared decision making in rheumatology. RMD Open 2020;6:e001121.

11 Forcino RC, Yen RW, Aboumrad M, et al. US-based cross-sectional survey of clinicians' knowledge and attitudes about shared decisionmaking across healthcare professions and specialties. BMJ Open 2018;8:e022730.

12 Drivenes K, Haaland Vegard Øksendal, Mesel T, et al. Practitioners' positive attitudes promote shared decision-making in mental health care. J Eval Clin Pract 2019;25:1041-9.

13 Durand M-A, DiMilia PR, Song J, et al. Shared decision making embedded in the undergraduate medical curriculum: a scoping review. PLoS One 2018;13:e0207012.

14 Elwyn G, Frosch D, Thomson R, et al. Shared decision making: a model for clinical practice. J Gen Intern Med 2012;27:1361-7.

15 Masi D, Gomez-Rexrode AE, Bardin R, et al. The "Preparation for Shared Decision-Making" Tool for Women With Advanced Breast Cancer: Qualitative Validation Study. J Particip Med 2019;11:e16511.

16 Spronk I, Burgers JS, Schellevis FG, et al. The availability and effectiveness of tools supporting shared decision making in metastatic breast cancer care: a review. BMC Palliat Care 2018;17:74.

17 Dwyer T, Wright S, Kulasegaram KM, et al. How to set the bar in competency-based medical education: standard setting after an objective structured clinical examination (OSCE). BMC Med Educ 2016;16:1.

18 Martin IG, Jolly B. Predictive validity and estimated cut score of an objective structured clinical examination (OSCE) used as an assessment of clinical skills at the end of the first clinical year. Med Educ 2002;36:418-25.

19 Majumder MAA, Kumar A, Krishnamurthy K, et al. An evaluative study of objective structured clinical examination (OSCE): students and examiners perspectives. Adv Med Educ Pract 2019;10:387-97.

20 Tucker Edmonds B, Hoffman SM, Laitano T, et al. Evaluating shared decision making in trial of labor after cesarean counseling using objective structured clinical examinations. MedEdPORTAL 2020;16:10891.

21 Akhigbe T. Summative objective structured clinical examination assessment: a mini review. Int J Med Rev 2018;5:140-2.

22 Obeidat RF, Homish GG, Lally RM. Shared decision making among individuals with cancer in non-Western cultures: a literature review. Oncol Nurs Forum 2013;40:454-63.

23 Müller E, Hahlweg P, Scholl I. What do stakeholders need to implement shared decision making in routine cancer care? A qualitative needs assessment. Acta Oncol 2016;55:1484-91.

24 Letvak S, Ruhm CJ, McCoy T. Depression in hospital-employed nurses. Clin Nurse Spec 2012;26:177-82.

25 Hinkin TR. A brief tutorial on the development of measures for use in survey questionnaires. Organ Res Methods 1998;1:104-21.

26 Norman GR, Streiner DL. PDQ statistics. 3rd edn. PMPH USA, Shelton, CT, 2003: 1-43.

27 Streiner DL, Norman GR. Health measurement scales.. In: A practical guide to their development and use. 3rd ed. Oxford, UK: Oxford University Press, 2003.

28 Lin $\mathrm{MH}$, Chang $\mathrm{TH}$, Lee $\mathrm{YH}$, et al. Developing and validating the nursing cultural competence scale in Taiwan. PLoS One 2019;14:e0220944.

29 Hair JF, Black WC, Babin BJ. Multivariate data analysis: a global perspective. 7th ed. Upper Saddle River, NJ: Pearson Prentice Hall, 2010.

30 Khattab AD, Rawlings B. Assessing nurse practitioner students using a modified objective structured clinical examination (OSCE). Nurse Educ Today 2001;21:541-50.

31 Kaiser HF. An index of factorial simplicity. Psychometrika 1974:39:31-6.

32 Ministry of Health and Welfare. Platform for shared decision making, 2018. Available: https://sdm.patientsafety.mohw.gov.tw/Public/ Medialnfo?sn $=12 \& i d=1332$

$33 \mathrm{Lin} \mathrm{M}-\mathrm{H}$, Hsu H-C. Effects of a cultural competence education programme on clinical nurses: a randomised controlled trial. Nurse Educ Today 2020;88:104385. 
34 Grimes DA, Schulz KF, David AG, Kenneth FS. Refining clinical diagnosis with likelihood ratios. Lancet 2005;365:1500-5.

35 Netemeyer RG, Bearden WO, Sharma S. Scaling procedures: issues and applications. Thousand Oaks, CA: Sage Publications, 2003. https://doi.org/10.4135/9781412985772

36 Riley RD, Snell KI, Ensor J, et al. Minimum sample size for developing a multivariable prediction model: PART II - binary and time-to-event outcomes. Stat Med 2019;38:1276-96.

37 Chung F-F, Wang P-Y, Lin S-C, et al. Shared clinical decision-making experiences in nursing: a qualitative study. BMC Nurs 2021;20:85.

38 Polit DF, Beck CT. Essentials of nursing research: Appraising evidence for nursing Practice. In: Wolters Kluwer health. 9th ed. Philadelphia, 2018.

39 DeVellis RF. Scale development: theory and applications. CA: Sage, 2017.

40 Lee Y-W, Hsieh Y-S, Chang F-H, et al. Experiences with making difficult decisions of the family caregivers of patients on prolonged mechanical ventilation: a qualitative study. Ann Palliat Med 2020;9:1742-51.

41 Bartlett MS. A note on the multiplying factors for various $\mathrm{x}^{2}$ approximations. J R Stat Soc 1954;16:296-8.

42 Alnaami N, Al Haqwi A, Masuadi E. Clinical learning evaluation questionnaire: a confirmatory factor analysis. Adv Med Educ Pract 2020;11:953-61.
43 Gates KM, Fisher ZF, Bollen KA. Latent variable GIMME using model implied instrumental variables (MIIVs). Psychol Methods 2020;25:227-42.

44 Hwang H, Takane Y, Jung K. Generalized structured component analysis with uniqueness terms for accommodating measurement error. Front Psychol 2017;8:2137.

45 Portney LG, Watkins MP. Foundations of clinical research: applications to practice. New Jersey: Prentice Hall Health, 2009.

46 Flora DB. Your coefficient alpha is probably wrong, but which coefficient omega is right? A tutorial on using $\mathrm{R}$ to obtain better reliability estimates. Adv Methods Pract Psychol Sci 2020;3:484-501.

47 Feißt M, Hennigs A, Heil J, Moosbrugger $\mathrm{H}$, et al. Refining scores based on patient reported outcomes - statistical and medical perspectives. BMC Med Res Methodol 2019;19:167.

48 Hosmer DW, Lemeshow S. Assessing the fit of model. In: Applied logistic regression. 2nd ed. New York, NJ: John Wiley \& Sons, 2000.

49 Boateng GO, Neilands TB, Frongillo EA, et al. Best practices for developing and validating scales for health, social, and behavioral research: a primer. Front Public Health 2018;6:149.

50 Burns N, Grove SK. The practice of nursing research: Conduct, critique \& utilization. 5th ed. St. Louis: Elsevier Saunders, 2005. 